Check for updates

Cite this: RSC Adv., 2017, 7, 56457

Received 29th September 2017 Accepted 8th December 2017

DOI: $10.1039 / c 7 r a 10775 g$

rsc.li/rsc-advances

\section{Asymmetric synthesis of 2,3-disubstituted indolines via an organocatalytic intramolecular Michael addition $\uparrow$}

\author{
Jusung Lee, Kwang Min Ko and Sung-Gon Kim (D) * \\ An asymmetric synthesis of 2,3-disubstituted indolines has been developed via an organocatalytic \\ intramolecular Michael addition. When a primary amine derived from cinchona alkaloid was used as the \\ catalyst, the intramolecular cyclization reaction of (E)-3-(2-(2-oxopropylamino)aryl)-1-arylprop-2-en-1- \\ ones afforded the corresponding cis-2,3-disubstituted indoline derivatives with high yields, moderate \\ diastereoselectivities, and excellent enantioselectivities (up to 2.7:1 dr and 99\% ee). Moreover, the \\ catalytic reaction of (E)-3-(2-(2-oxopropylamino)aryl)-1-alkylprop-2-en-1-ones afforded trans-2,3- \\ disubstituted indolines in high yields and with good-to-excellent diastereo- and enantioselectivities (up \\ to 20 : $1 \mathrm{dr}$ and $99 \%$ ee).
}

Optically active indolines are structurally essential elements in biologically active natural alkaloids and chiral pharmaceuticals. ${ }^{1}$ Among various indolines, chiral 2,3-disubstituted indolines are significant building blocks in both synthetic and medicinal chemistry because they are present in numerous natural products and pharmaceuticals including (-)-strychnine, aspidospermidine, WAY-163909, and (-)-physostigmine, as shown in Fig. $1 .^{2}$ They have two chiral centers leading to four possible diastereomers, each of which can exhibit significantly different chemical and biological activities. Therefore, it is challenging and interesting to develop novel synthetic methodologies for constructing enantioenriched 2,3-disubstituted indoline derivatives in synthetic organic chemistry.

Consequently, diverse strategies have been developed for the synthesis of enantioenriched indolines. ${ }^{3}$ Among these, the most powerful tool for the asymmetric synthesis of 2,3-disubstituted indolines is the catalytic hydrogenation of substituted indole derivatives. ${ }^{4}$ Although asymmetric hydrogenation is one of the most straightforward methods in terms of simplicity and atom efficiency, this transformation affords only cis-2,3-disubstituted indolines. Catalytic kinetic resolution is also used to obtain such chiral indolines. ${ }^{5}$ Recently, some significant syntheses of optically active indolines have been achieved using asymmetric intramolecular cyclization reactions such as electrophilic cyclization. ${ }^{6}$ The benefit of these reactions is the easy introduction of various functional groups at the 2- and 3-positions of indoline. Kündig and co-workers reported that the reaction of $\mathrm{N}$-aryl, $\mathrm{N}$ -

Department of Chemistry, Kyonggi University, 154-42, Gwanggyosan-ro, Yeongtong-gu, Suwon 16227, Republic of Korea. E-mail: sgkim123@kyonggi.ac.kr

$\dagger$ Electronic supplementary information (ESI) available. CCDC 1527668. For ESI and crystallographic data in CIF or other electronic format see DOI: 10.1039/c7ra10775g branched alkyl carbamates with a Pd-catalyst bearing chiral Nheterocyclic carbene ligand, giving enantioenriched 2,3-disubstituted indolines. ${ }^{6 c}$ Xiao and co-workers developed an innovative cycloaddition strategy for the enantioselective synthesis of trans2,3-disubstituted indolines, involving the Pd-catalyzed decarboxylation-cycloaddition reaction of vinyl benzoxazinanones with sulfur ylides. ${ }^{6 b}$ More recently, Buchwald and co-workers reported an efficient $\mathrm{Cu}-\mathrm{H}$-catalyzed strategy using 2-alkenylimine precursors obtained from alkenylanilines and aromatic aldehydes for the highly diastereo- and enantioselective synthesis of cis-2,3-disubstituted indolines. ${ }^{6 a}$ However, to the best of our knowledge, the synthesis of chiral 2,3-disubstituted indolines by asymmetric cycloaddition using organocatalyst has not been reported, even though asymmetric organocatalysis has significantly progressed over the past decade. ${ }^{7,8}$

Within the framework of our program devoted to the development of stereoselective cascade reactions of $o$-aminophenyl

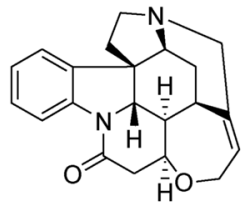

(-)-Strychnine<smiles>c1cc2c3c(c1)[C@H]1CCC[C@H]1N3CCNC2</smiles>

WAY-163909

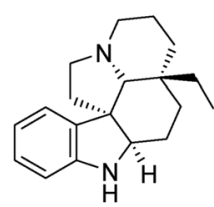

Aspidospermidine<smiles>CNC(=O)Oc1ccc2c(c1)C1(C)CCN(C)[C@]1(NC)N2C</smiles>

(-)-Physostigmine
Fig. 1 Representative chiral 2,3-disubstituted indoline derivatives. 
$\alpha, \beta$-unsaturated compounds, ${ }^{9}$ we recently reported an azaalkylation/Michael cascade reaction of 2-(tosylamino)phenyl $\alpha, \beta$-unsaturated ketones with $\alpha$-bromoacetophenones to afford cis-2,3-disubstituted indolines in high yields and with excellent diastereoselectivities (Scheme 1, eqn (1)). ${ }^{\mathbf{1 0}}$ In this reaction, the nitrogen atom of 2-(tosylamino)phenyl $\alpha, \beta$-unsaturated ketone attacks $\alpha$-bromoacetophenone through $\mathrm{S}_{\mathrm{N}} 2$ reaction to first afford 2-(2-oxoalkyltosylamino)phenyl $\alpha, \beta$-unsaturated ketone, followed by an intramolecular Michael addition. These findings prompted us to investigate the asymmetric synthesis of 2,3disubstituted indolines. We envisioned that optically active 2,3disubstituted indoline derivatives can be accessed by the intramolecular Michael addition of 2-(2-oxoalkyltosylamino) phenyl $\alpha, \beta$-unsaturated ketone using a chiral organocatalyst (Scheme 1, eqn (2)).

First, (E)-3-(2-(2-oxopropyltosylamino)phenyl)-1-phenylprop2-en-1-one 1a was selected as the model substrate, and its intramolecular Michael addition was investigated using a bifunctional catalytic system (Fig. 2). Initially, the model reaction was performed using $10 \mathrm{~mol} \%$ of Takemoto bifunctional thiourea catalyst $\mathbf{I}^{\mathbf{1 1}}$ in toluene at room temperature (Table 1, entry 1). The Michael reaction was completed within $48 \mathrm{~h}$ and afforded the desired indoline $2 \mathrm{a}$ in $92 \%$ yield and with moderated diastereo- and enantioselectivities. Encouraged by these results, several bifunctional catalysts were screened to obtain a higher enantioselectivity. Cinchona-derived thiourea catalyst $\mathbf{I I}^{\mathbf{1 2}}$ gave almost the same results as catalyst $\mathbf{I}$ (Table 1, entry 1 ). Next, bifunctional primary amine catalysts $\mathbf{~ I I I}^{\mathbf{1 3}}$ derived from cinchona alkaloids were screened; they were found to be promising catalysts for this intramolecular reaction (Table 1, entries 3-6). When primary amine catalysts IIIa-c were used, the reaction smoothly afforded the corresponding product $2 \mathrm{a}$ with enantioselectivities of 64,62 , and $77 \%$ ee for the major diastereomer, respectively (Table 1 , entries 3-5). The use of a primary amine catalyst IIId significantly increased the ee value of product 2a (Table 1, entry 6, 88\% ee for the major isomer). Although a low diastereoselectivity was obtained, catalyst IIId

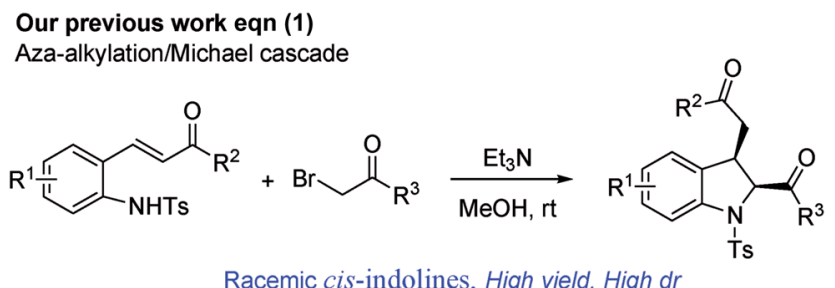

This work eqn (2)

Michael reaction using a chiral organocatalyst
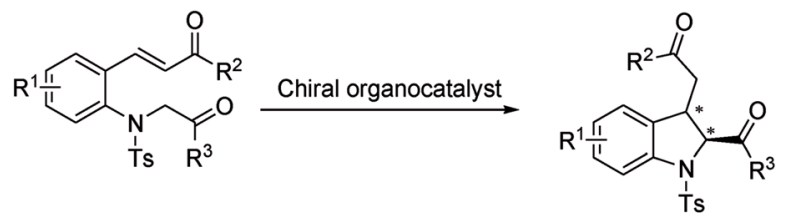

Chiral indolines, High yield, High ee

Scheme 1 Stereoselective synthesis optically active 2,3-disubstituted indolines.<smiles>CN(C)[C@H]1CCCC[C@H]1NC(=S)Nc1cc(C(F)(F)F)cc(C(F)(F)F)c1</smiles>

I

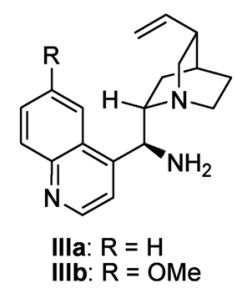

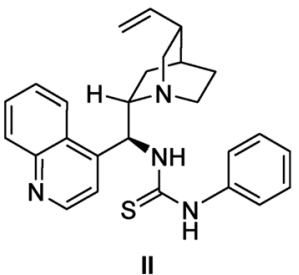

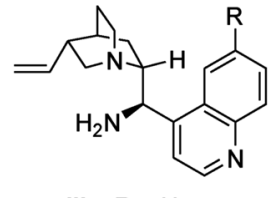

IIIc: $\mathrm{R}=\mathrm{H}$ IIId: $\mathrm{R}=\mathrm{OMe}$
Fig. 2 Evaluated bifunctional chiral organocatalysts.

Table 1 Catalyst screening ${ }^{a}$<smiles>CC(=O)CN([12CH3])c1ccccc1/C=C/C(=O)c1ccccc1</smiles>

1a
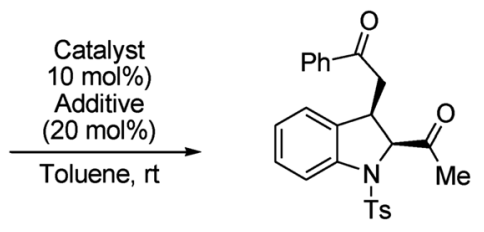

2a

\begin{tabular}{lllllll} 
Entry & Catalyst & Additive & Time (h) & Yield $^{b}(\%)$ & cis/trans $^{c}$ & ee $^{d, e}(\%)$ \\
\hline 1 & I & None & 48 & 92 & $67: 33$ & $41 / 23$ \\
2 & II & None & 168 & 94 & $66: 34$ & $33 / 31$ \\
3 & III $^{a}$ & AcOH & 168 & 62 & $15: 85$ & $38 / 64$ \\
4 & III $^{b}$ & AcOH & 240 & 76 & $31: 69$ & $52 / 62$ \\
5 & III $^{c}$ & AcOH & 168 & 61 & $20: 80$ & $36 / 77$ \\
6 & III $^{d}$ & AcOH & 120 & 86 & $53: 47$ & $88 / 85$ \\
7 & III $^{d}$ & None & 240 & 85 & $41: 59$ & $69 / 21$
\end{tabular}

${ }^{a}$ All reactions were performed with $0.1 \mathrm{mmol}$ of $1 \mathrm{a}$, catalyst (10 mol\%), and additive $(20 \mathrm{~mol} \%)$ in toluene $(0.2 \mathrm{M}) .{ }^{b}$ Isolated yield after chromatographic purification. ${ }^{c}$ Determined by ${ }^{1} \mathrm{H}$ NMR analysis. ${ }^{d}$ The ee values were determined by chiral HPLC analysis. ${ }^{e}$ ee values cis/trans diastereomers.

was the best choice for the model reaction in terms of the chemical yield and enantioselectivity of the major diastereomer. In addition, an acid additive was an important factor in this reaction; the reaction without using an additive showed lower reactivity and enantioselectivity than those using an additive (Table 1, entry $6 v s$. entry 7 ).

After confirming primary amine IIId as the optimum catalyst for this Michael reaction, other factors influencing the reaction such as the acid additive, solvent, and reaction temperature were thoroughly investigated (Table 2). First, an acid additive was determined as essential to both the reactivity and enantioselectivity of the reaction. 2-Nitrobenzoic acid gave superior results with respect to reaction rate and enantioselectivity (Table 2, entry 6). Moreover, this Michael reaction was found to be sensitive to the solvent. In toluene, $\mathrm{CH}_{2} \mathrm{Cl}_{2}, \mathrm{ClCH}_{2} \mathrm{CH}_{2} \mathrm{Cl}$, 


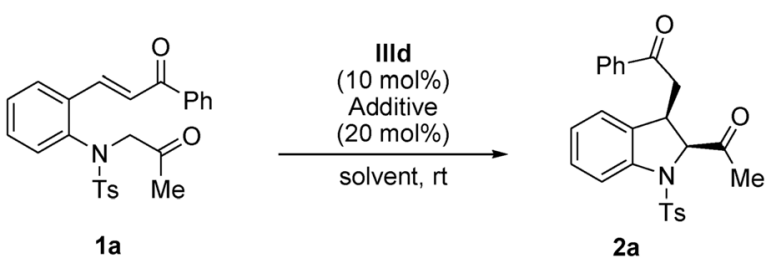

1a

$2 \mathrm{a}$

\begin{tabular}{|c|c|c|c|c|c|c|}
\hline Entry & Additive & Solvent & Time (h) & Yield $^{b}(\%)$ & cis/trans $^{c}$ & $\mathrm{ee}^{d, e}(\%)$ \\
\hline 1 & $\mathrm{AcOH}$ & Toluene & 120 & 85 & $41: 59$ & $88 / 85$ \\
\hline 2 & $\mathrm{CF}_{3} \mathrm{CO}_{2} \mathrm{H}$ & Toluene & 72 & 91 & $59: 41$ & $91 / 88$ \\
\hline 4 & $\mathrm{PhCO}_{2} \mathrm{H}$ & Toluene & 24 & 95 & $59: 41$ & $94 / 88$ \\
\hline 5 & $4-\mathrm{NO}_{2} \mathrm{BzOH}$ & Toluene & 6 & 85 & $40: 60$ & $93 / 89$ \\
\hline 6 & $2-\mathrm{NO}_{2} \mathrm{BzOH}$ & Toluene & 8 & 94 & $64: 36$ & $96 / 88$ \\
\hline 9 & $2-\mathrm{NO}_{2} \mathrm{BzOH}$ & $\mathrm{CHCl}_{3}$ & 6 & 96 & $60: 40$ & $96 / 87$ \\
\hline 10 & $2-\mathrm{NO}_{2} \mathrm{BzOH}$ & EtOAc & 4 & 96 & $60: 40$ & $96 / 90$ \\
\hline 11 & $2-\mathrm{NO}_{2} \mathrm{BzOH}$ & $\mathrm{CH}_{3} \mathrm{CN}$ & 96 & 41 & $23: 77$ & $51 / 36$ \\
\hline 12 & $2-\mathrm{NO}_{2} \mathrm{BzOH}$ & THF & 96 & 73 & $52: 48$ & $89 / 68$ \\
\hline 13 & $2-\mathrm{NO}_{2} \mathrm{BzOH}$ & $\mathrm{MeOH}$ & 96 & 50 & $20: 80$ & $48 / 45$ \\
\hline $14^{f}$ & $2-\mathrm{NO}_{2} \mathrm{BzOH}$ & EtOAc & 24 & 98 & $63: 37$ & $98 / 94$ \\
\hline
\end{tabular}

${ }^{a}$ Unless otherwise specified, the reactions were performed with $0.1 \mathrm{mmol}$ of 1a, catalyst IIId (10 mol\%), and additive (20 mol\%) in solvent (0.2 M).

${ }^{b}$ Isolated yield after chromatographic purification. ${ }^{c}$ Determined by ${ }^{1} \mathrm{H}$ NMR analysis. ${ }^{d}$ The ee values were determined by chiral HPLC analysis. ${ }^{e}$ ee values cis/trans diastereomers. ${ }^{f}$ Reaction performed at $0{ }^{\circ} \mathrm{C} .{ }^{g}$ Reaction performed with $10 \mathrm{~mol} \% 2-\mathrm{NO}_{2} \mathrm{BzOH}$ at $0{ }^{\circ} \mathrm{C}$.

$\mathrm{CHCl}_{3}$, and EtOAc, the reaction smoothly proceeded and completed within $10 \mathrm{~h}$, affording the corresponding product $2 \mathrm{a}$ in high yields and with excellent enantioselectivities for both diastereomers (Table 2, entries 6-10). In $\mathrm{CH}_{3} \mathrm{CN}$, THF and $\mathrm{MeOH}$, the reaction was completed in a longer time than in other solvents with moderate yields and enantioselectivities, even though a high enantioselectivity was observed for the major diastereomer in THF (Table 2, entries 11-13). Although a low diastereoselectivity was observed in EtOAc, both the diastereomers were obtained in the highest yields and enantioselectivities (Table 2, entry 10). Therefore, EtOAc was selected as the most suitable solvent for this asymmetric intramolecular Michael addition. A lower reaction temperature provided a better stereocontrol. The desired product was achieved in an excellent yield and with enantioselectivities (98\% ee cis isomer; 94\% ee trans isomer) and a moderate diastereoselectivity (cis/ trans, 63 : 37) (Table 2, entry 14). In addition, when the amount of 2-nitrobenzoic acid was reduced from $20 \mathrm{~mol} \%$ to $10 \mathrm{~mol} \%$, the enantioselectivity decreased (Table 2 , entry 14 ).

With the optimized reaction conditions in hand ( 1 equiv. of 1, $10 \mathrm{~mol} \%$ catalyst IIId, and $20 \mathrm{~mol} \%$ 2-nitrobenzoic acid in EtOAc at $0{ }^{\circ} \mathrm{C}$ ), the substrate scope of the reaction was investigated, and the results are summarized in Table 3 . This transformation has a broad substrate scope. The reactions of all the substrates smoothly afforded the corresponding indolines in moderate-to-high yields (62-97\%) and with excellent enantioselectivities (93-99\% ee) for the major diastereomer in all the cases except $p$-Me-substituted substrate 1m. Gratifyingly, the electronic nature of the $\mathrm{R}^{1}$ group slightly affected the reaction efficiencies with regard to enantioselectivities and yields. Both electron-withdrawing (Table 3, entries 2-4) and electrondonating (Table 3, entries 5 and 6) groups were well tolerated; the obtained diastereoselectivities were still low in all the cases. For the $\mathrm{R}^{2}$ group, the reactions proceeded well with electronwithdrawing substituents (Table 3, entries 7-12) and electrondonating substituents (Table 3, entries 12-14). Notably, a substrate bearing an ortho- and para-substituted halogen group on the phenyl $\mathrm{R}^{2}$ group afforded the corresponding product with a higher diastereoselectivity than the other substrates. A substrate bearing both ortho-substituted chloro group provided trans-2,3-disubstituted indoline $2 \mathbf{j}$ in the major diastereomer (cis/trans, 33 : 67) (Table 3, entry 10). Moreover, a heteroaromatic group was introduced at the $\mathrm{R}^{2}$ position; the reaction proceeded rapidly, affording the corresponding products 20 and 2p in high yields and with good enantiocontrol (over 91\% ee, Table 3, entries 15 and 16).

To evaluate the practical applications of this methodology, a gram-scale reaction using the standard conditions was conducted; product 2a was obtained without any significant changes in the yield or stereoselectivity (Scheme 2). The absolute configuration of product cis-2d was determined by X-ray crystallographic analysis and found to be $2 S, 3 R \cdot{ }^{14}$ The configurations of the other products were assigned by analogy. 
Table 3 Substrate scope of the organocatalytic asymmetric intramolecular Michael addition ${ }^{a}$

\begin{tabular}{|c|c|c|c|c|c|c|c|}
\hline Entry & $\mathrm{R}^{1}$ & $\mathrm{R}^{2}$ & Time (h) & 2 & Yield $^{b}(\%)$ & cis/trans ${ }^{c}$ & $\mathrm{ee}^{d, e}(\%)$ \\
\hline 1 & $\mathrm{H}$ & $\mathrm{Ph}$ & 28 & $2 a$ & 97 & $63: 37$ & $98 / 94$ \\
\hline 2 & $4-\mathrm{Cl}$ & $\mathrm{Ph}$ & 36 & $2 \mathbf{b}$ & 96 & $58: 42$ & $95 / 93$ \\
\hline 3 & $5-\mathrm{Cl}$ & $\mathrm{Ph}$ & 48 & $2 c$ & 88 & $58: 42$ & 99/95 \\
\hline 4 & $4-\mathrm{Br}$ & $\mathrm{Ph}$ & 48 & $2 d$ & 97 & $56: 44$ & 99/95 \\
\hline 5 & 4-Me & $\mathrm{Ph}$ & 56 & $2 e$ & 91 & $60: 40$ & 99/93 \\
\hline 6 & 4,5-MeO & $\mathrm{Ph}$ & 72 & $2 \mathrm{f}$ & 62 & $58: 42$ & $95 / 97$ \\
\hline 7 & $\mathrm{H}$ & $p-\mathrm{ClC}_{6} \mathrm{H}_{4}$ & 36 & $2 \mathrm{~g}$ & 86 & $61: 39$ & $92 / 76$ \\
\hline 8 & $\mathrm{H}$ & $m-\mathrm{ClC}_{6} \mathrm{H}_{4}$ & 56 & $2 \mathrm{~h}$ & 93 & $51: 49$ & $92 / 90$ \\
\hline 9 & $\mathrm{H}$ & $o-\mathrm{ClC}_{6} \mathrm{H}_{4}$ & 48 & $2 \mathbf{i}$ & 96 & $73: 27$ & $94 / 92$ \\
\hline 10 & $\mathrm{H}$ & $2,6-\mathrm{ClC}_{6} \mathrm{H}_{3}$ & 96 & $2 \mathbf{j}$ & 83 & $33: 67$ & $91 / 90$ \\
\hline 11 & $\mathrm{H}$ & $p-\mathrm{BrC}_{6} \mathrm{H}_{4}$ & 48 & $2 \mathbf{k}$ & 82 & $70: 30$ & 98/94 \\
\hline 12 & $\mathrm{H}$ & $p-\mathrm{FC}_{6} \mathrm{H}_{4}$ & 36 & 21 & 95 & $65: 35$ & $95 / 86$ \\
\hline 13 & $\mathrm{H}$ & $p-\mathrm{MeC}_{6} \mathrm{H}_{4}$ & 36 & $2 \mathrm{~m}$ & 85 & $54: 46$ & $90 / 84$ \\
\hline 14 & $\mathrm{H}$ & $p-\mathrm{MeOC}_{6} \mathrm{H}_{4}$ & 48 & $2 n$ & 91 & $55: 45$ & $96 / 89$ \\
\hline 15 & $\mathrm{H}$ & 2-Furanyl & 36 & 20 & 92 & $47: 53$ & $92 / 91$ \\
\hline 16 & $\mathrm{H}$ & 2-Thienyl & 24 & $2 p$ & 86 & $43: 57$ & $94 / 94$ \\
\hline
\end{tabular}

${ }^{a}$ All reactions were performed with $0.1 \mathrm{mmol}$ of 1 , catalyst IIId $(10 \mathrm{~mol} \%)$, and $2-\mathrm{NO}_{2} \mathrm{BzOH}(20 \mathrm{~mol} \%)$ in EtOAc $(0.2 \mathrm{M})$ at $0{ }^{\circ} \mathrm{C} .{ }^{b}$ Isolated yield after chromatographic purification. ${ }^{c}$ Determined by ${ }^{1} \mathrm{H}$ NMR analysis. ${ }^{d}$ The ee values were determined by chiral HPLC analysis. ${ }^{e}$ ee values cis/trans diastereomers.
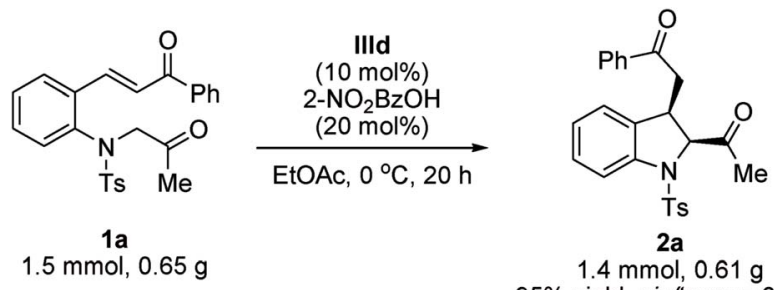

$95 \%$ yield, cis/trans $=62: 38$ ee $=98 \%$ (cis), $94 \%$ (trans)

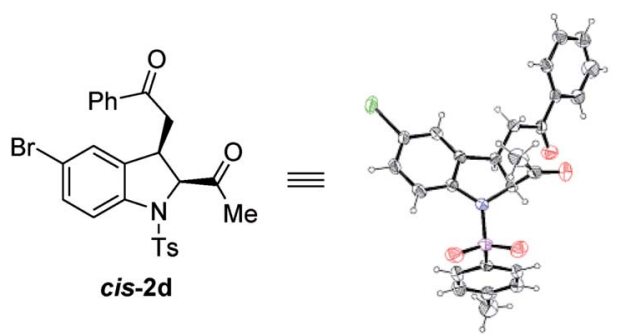

Scheme 2 Gram-scale synthesis of indoline 2a and X-ray crystal structure of cis-2d.

Furthermore, the reactions of $(E)$-3-(2-(2-oxopropylamino) aryl)-1-alkylprop-2-en-1-ones bearing an alkyl group at the $\mathrm{R}^{2}$ position, such as methyl, cyclopropyl and $t$-butyl, smoothly afforded the corresponding 2,3-disubstituted indolines in high yields and with excellent enantioselectivities (Table 4, entries 1-
3). To our delight, $t$-butyl $\alpha, \beta$-unsaturated ketone provided the desired trans-2,3-disubstituted indoline 4c with an excellent diastereomeric ratio (trans/cis, $13: 1$ ) and enantioselectivity (98\% ee; Table 4, entry 3$).{ }^{15}$ Encouraged by the excellent results obtained using $t$-butyl $\alpha, \beta$-unsaturated ketone, the scope of our strategy was further extended. No obvious impact was observed on either the reaction efficiency or stereoselectivity, regardless of the electronic nature, bulkiness, or position of the substituent on the benzene ring of (E)-3-(2-(2-oxopropylamino)aryl)-1-tbutylprop-2-en-1-ones. Both electron-withdrawing groups (Table 4, entries 4-6) and electron-donating groups (Table 4, entries 7 and 8) were well tolerated, and all the products were obtained in good yields and with excellent diastereoselectivities (trans/cis, $13: 1$ to $>25: 1$ ) and enantioselectivities (93-99\% ee).

On the basis of our experimental results, a plausible transition state for this asymmetric Michael reaction is shown in Scheme 3. The Si-face attack of anti-enamine to the Re-face of $t$ butyl $\alpha, \beta$-unsaturated ketone led to the formation of the $S, S$ configurated trans-indoline $\mathbf{4 c .}$

To further demonstrate the synthetic utility of this methodology, we have illustrated a representative procedure to convert the enantioenriched idoline product into the corresponding alkenyl ester 5 (Scheme 4). The reaction of trans-4c with methyl(triphenylphosphoranylidene)acetate provided Wittig product $\mathbf{5}$ in moderate yield without affecting the enantioselectivity. 
Table 4 Distereo- and enantioselective synthesis of trans-2,3-disubstituted indoline ${ }^{a}$

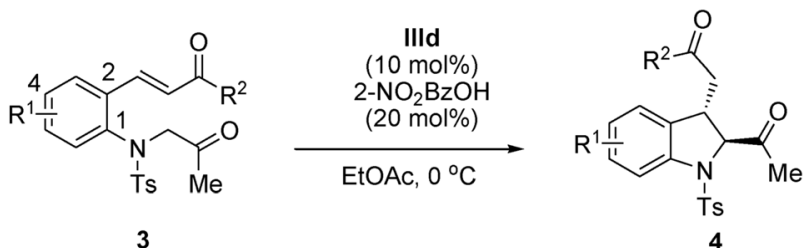

\begin{tabular}{|c|c|c|c|c|c|c|c|}
\hline Entry & $\mathrm{R}^{1}$ & $\mathrm{R}^{2}$ & Time (h) & 4 & Yield $^{b}(\%)$ & trans/cis ${ }^{c}$ & $\mathrm{ee}^{d}(\%)$ \\
\hline 1 & $\mathrm{H}$ & $\mathrm{Me}$ & 72 & $4 a$ & 65 & $1: 1.5$ & $84 / 87$ \\
\hline 2 & $\mathrm{H}$ & Cyclopropyl & 48 & $4 \mathrm{~b}$ & 93 & $4: 1$ & 94 \\
\hline 4 & $4-\mathrm{Cl}$ & $t$-Bu & 12 & $4 d$ & 97 & $13: 1$ & 95 \\
\hline 5 & 5-Cl & $t$-Bu & 48 & $4 e$ & 78 & $>25: 1$ & 93 \\
\hline 6 & $4-\mathrm{Br}$ & $t-\mathrm{Bu}$ & 12 & 4f & 92 & $15: 1$ & 98 \\
\hline
\end{tabular}

${ }^{a}$ Unless otherwise specified, the reactions were performed with $0.1 \mathrm{mmol}$ of 3, catalyst IIId (10 mol\%), and 2- $\mathrm{NO}_{2} \mathrm{BzOH}(20 \mathrm{~mol} \%)$ in EtOAc (0.2 M) at $0{ }^{\circ} \mathrm{C} .{ }^{b}$ Isolated yield after chromatographic purification. ${ }^{c}$ Determined by ${ }^{1} \mathrm{H}$ NMR analysis. ${ }^{d}$ The ee values were determined by chiral HPLC analysis.

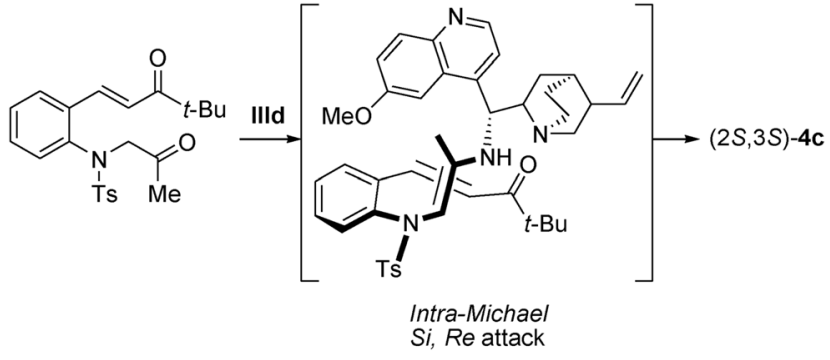

Scheme 3 Plausible transition state.
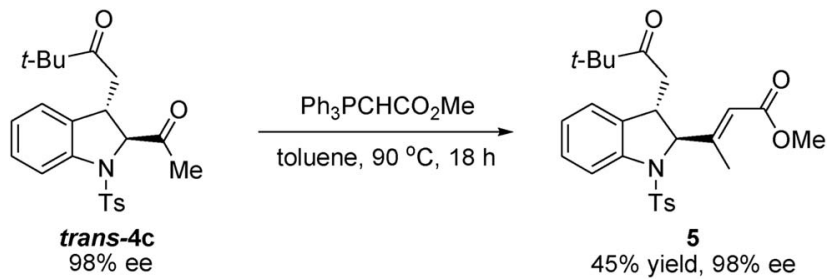

Scheme 4 The synthetic transformation of indoline trans-4c

\section{Conclusions}

In conclusion, we have developed an efficient method for the asymmetric synthesis of 2,3-disubstituted indolines through an organocatalytic intramolecular Michael addition. The reaction of (E)-3-(2-(2-oxopropylamino)aryl)-1-arylprop-2-en-1-ones afforded the corresponding cis-2,3-disubstituted indoline derivatives in high yields and with moderate diastereoselectivities and excellent enantioselectivities (up to $2.7: 1 \mathrm{dr}$ and $99 \%$ ee) using a primary amine derived from a cinchona alkaloid as the catalyst. Moreover, the catalytic reaction of $(E)-3-$ (2-(2-oxopropylamino)aryl)-1-alkylprop-2-en-1-ones helped to develop an unprecedented approach for the synthesis of chiral trans-2,3-disubstituted indolines in high yields and with goodto-excellent diastereo- and enantioselectivities (up to >25:1 dr, and $99 \%$ ee).

\section{Conflicts of interest}

There are no conflicts to declare.

\section{Acknowledgements}

This research was supported by the Nanomaterial Technology Development Program through the National Research Foundation of Korea (NRF) funded by the Ministry of Science, ICT and Future Planning (NRF-2012M3A7B4049645) and the Basic Science Research Program through NRF funded by the Ministry of Education (NRF-2016R1D1A1A09916621).

\section{Notes and references}

1 For recent reviews, see: (a) E. Fattorusso and O. TaglialatelaScafati, Modern Alkaloids, Wiley-VCH, Weinheim, 2008; (b) G. M. Cragg, D. G. I. Kingston and D. J. Newman, Anticancer Agents from Natural Products, CRC, Boca Raton, FL, 2012; (c) D. Crich and A. Banerjee, Acc. Chem. Res., 2007, 40, 151; (d) D. L. Boger, C. W. Boyce, R. M. Garbaccio and J. A. Goldberg, Chem. Rev., 1997, 97, 787.

2 (a) T. Bui, S. Syed and C. F. Barbas III, J. Am. Chem. Soc., 2009, 131, 8758; (b) H. Zhang, J. Boonsombat and A. Padwa, Org. Lett., 2007, 9, 279; (c) K. L. Marquis, A. L. Sabb, S. F. Logue, J. A. Brennan, M. J. Piesla, T. A. Comery, S. M. Grauer, C. R. Ashby Jr, H. Q. Nguyen, L. A. Dawson, J. E. Barret, 
G. Stack, H. Y. Meltzer, B. L. Harrison and S. RosenzweigLipson, J. Pharmacol. Exp. Ther., 2007, 320, 486; (d) R. Iyengar, K. Schildknegt, M. Morton and J. Aube, J. Org. Chem., 2005, 70, 10645.

3 (a) D. Zhang, H. Song and Y. Qin, Acc. Chem. Res., 2011, 44, 447; (b) D. Liu, G. Zhao and L. Xiang, Eur. J. Inorg. Chem., 2010, 3975, and references therein.

4 For recent selected examples, see: (a) Z. Yang, F. Chen, Y. He, N. Yang and Q.-H. Fan, Angew. Chem., Int. Ed., 2016, 55, 13863; (b) Y.-C. Zhang, J.-J. Zhao, F. Jiang, S.-B. Sun and F. Shi, Angew. Chem., Int. Ed., 2014, 53, 13912; (c) C. Romano, M. Jia, M. Monari, E. Manoni and M. Bandini, Angew. Chem., Int. Ed., 2014, 53, 13854; (d) L. Chen, C. Wang, L. Zhou and J. Sun, Adv. Synth. Catal., 2014, 356, 2224; (e) Y. Duan, M.-W. Chen, Q.-A. Chen, C.-B. Yu and Y.-G. Zhou, Org. Biomol. Chem., 2012, 10, 1235; $(f)$ Y.-C. Xiao, C. Wang, Y. Yao, J. Sun and Y.-C. Chen, Angew. Chem., Int. Ed., 2011, 50, 10661; (g) Y. Duan, M.-W. Chen, Z.-S. Ye, D.-S. Wang, Q.-A. Chen and Y.-G. Zhou, Chem.Eur. J., 2011, 17, 7193; (h) M.-W. Chen, C.-B. Yu, Y. Duan and G.-F. Jiang, Chem. Sci., 2011, 2, 803.

5 (a) K. Saito, Y. Shibata, M. Yamanaka and T. Akiyama, J. Am. Chem. Soc., 2013, 135, 11740; (b) M. Lopez-Iglesias, E. Busto, V. Gotor and V. Gotor-Fernández, J. Org. Chem., 2012, 77, 8049; (c) X. L. Hou and B. H. Zheng, Org. Lett., 2009, 11, 789; (d) F. O. Arp and G. C. Fu, J. Am. Chem. Soc., 2006, 128, 14264; (e) V. Gotor-Fernández, P. Fernández-Torres and V. Gotor, Tetrahedron: Asymmetry, 2006, 17, 2558.

6 (a) E. Ascic and S. L. Buchwald, J. Am. Chem. Soc., 2015, 137, 4666; (b) T.-R. Li, F. Tan, L.-Q. Lu, Y. Wei, Y.-N. Wang, Y.-Y. Liu, Q.-Q. Yang, J.-R. Chen, D.-Q. Shi and W.-J. Xiao, Nat. Commun., 2014, 5, 5500; (c) D. Katayev, M. Nakanishi, T. Bürgi and E. T. Kündig, Chem. Sci., 2012, 3, 1422; (d) K. H. Kang, J. Do and Y. S. Park, J. Org. Chem., 2012, 77, 808; (e) J. L. García Ruano, A. Parra, V. Marcos, C. del Pozo, S. Catalán, S. Monteagudo, S. Fustero and A. Poveda, J. Am. Chem. Soc., 2009, 131, 9432; (f) J. L. García Ruano, J. Alemán, S. Catalán, V. Marcos, S. Monteagudo, A. Parra, C. del Pozo and S. Fustero, Angew. Chem., Int. Ed., 2008, 47, 7941.

7 For examples of organocatalytic asymmetric syntheses of 2substituted indolines via cycloaddition, see: (a) R. Miyaji, K. Asano and S. Matsubara, Org. Lett., 2013, 15, 3658; (b) S. Fustero, C. del Pozo, C. Mulet, R. Lazaro and
M. Sánchez-Roselló, Chem.-Eur. J., 2011, 17, 14267; (c) S. Fustero, J. Moscardó, D. Jiménez, M. D. Pérez-Carrión, M. Sánchez-Roselló and C. del Pozo, Chem.-Eur. J., 2008, 14, 9868; (d) E. C. Carlson, L. K. Rathbone, H. Yang, N. D. Collett and R. G. Carter, J. Org. Chem., 2008, 73, 5155. 8 For selected reviews on organocatalysis, see: (a) A. Moyano and R. Rios, Chem. Rev., 2011, 111, 4703; (b) H. Pellissier, Recent Developments in Asymmetric Organocatalysis, RSC, Cambridge, 2010; (c) S. Bertelsen and K. A. Jørgensen, Chem. Soc. Rev., 2009, 38, 2178; (d) A. Dondoni and A. Massi, Angew. Chem., Int. Ed. Engl., 2008, 47, 4638; (e) P. I. Dalko, Enantioselective Organocatalysis, Wiley-VCH, Weinheim, 2007.

9 (a) Y. Lee, S. Heo and S.-G. Kim, Adv. Synth. Catal., 2015, 357, 1545; (b) H. Kim and S.-G. Kim, Tetrahedron Lett., 2015, 56, 4819; (c) M. Yu and S.-G. Kim, Tetrahedron Lett., 2015, 56, 4159; (d) A. Kim, C. Kim and S.-G. Kim, Bull. Korean Chem. Soc., 2015, 36, 417; (e) Y. Lee and S.-G. Kim, J. Org. Chem., 2014, 79, 8234; $(f)$ K.-T. Kang and S.-G. Kim, Synthesis, 2014, 46, 3365; (g) S. Kim, K.-T. Kang and S.-G. Kim, Tetrahedron, 2014, 70, 5114; $(h)$ C. Kim and S.-G. Kim, Tetrahedron: Asymmetry, 2014, 25, 1376; (i) S. Heo, S. Kim and S.-G. Kim, Tetrahedron Lett., 2013, 54, 4978.

10 M. Yu and S.-G. Kim, Tetrahedron Lett., 2015, 56, 7034.

11 (a) S. Sakamoto, T. Inokuma and Y. Takemoto, Org. Lett., 2011, 13, 6374; (b) T. Okino, Y. Hoashi and Y. Takemoto, J. Am. Chem. Soc., 2003, 125, 12672.

12 For selected reviews on bifunctional cinchona thiourea catalysis, see: (a) B. Han, J.-L. Li, Y.-C. Xiao, S.-L. Zhou and Y.-C. Chen, Curr. Org. Chem., 2011, 15, 4128; (b) Y. Takemoto, Chem. Pharm. Bull., 2010, 58, 593; (c) C. E. Song, Cinchona Alkaloids in Synthesis \& Catalysis, Wiley-VCH, Weinheim, 2009; (d) S. J. Connon, Chem. Commun., 2008, 2499.

13 For selected reviews on primary amine catalysis, see: $(a)$ P. Melchiorre, Angew. Chem., Int. Ed., 2012, 51, 9748; (b) L.-W. Xu, J. Luo and Y. Lu, Chem. Commun., 2009, 1807; (c) F. Peng and Z. Shao, J. Mol. Catal. A: Chem., 2008, 285, 1.

14 CCDC 1527668 (2d) contains the supplementary crystallographic data for this paper. $\dagger$

15 The relative stereochemistry of compound 4 (trans-isomer) was established by the distinguished chemical shift in $1 \mathrm{H}$ NMR of the trans-isomer and by NOESY. 